\title{
Pharmacovigilance: towards the next millennium
}

\section{Patrick C. Waller}

Medicines Control Agency, Market Towers, 1, Nine Elms Lane, London SW8 5NQ

\begin{abstract}
Although the concept of monitoring the safety of marketed medicines has been with us since the 1960s, at the beginning of the decade few people outside France used the word 'pharmacovigilance'. In recent years, however, the field has moved on and acquired itself a new name. Pharmacovigilance is now accepted to be a continuous process of evaluation accompanied by steps to improve safe use of medicines which involves pharmaceutical companies, regulatory authorities, health professionals and patients. The methodologies have broadened to encompass many different types of study, with spontaneous reporting remaining the cornerstone. The British Journal of Clinical Pharmacology has responded by publishing an increasing number of articles relating to pharmacovigilance, and a recent editorial entitled 'Pharmacovigilance in the 1990s' [1].

In this month's issue we publish the first two papers in a series which will review the state of pharmacovigilance as we approach the turn of the millennium. On page 419, Garcia Rodriguez and Perez Gutthann discuss the use of the UK General Practice Research Database for pharmacoepide-
\end{abstract}

Correspondence: Dr P. C. Waller, Medicines Control Agency, Market Towers, I Nine Elms Lane, London SW8 $5 \mathrm{NQ}$. miology, while on page 427 Talbot and Nilsson review the changing face of pharmacovigilance from an industry perspective. Future articles will focus particularly on the variety of methods by which the risks and benefits of medicines can be assessed.

The 1990s have already been an important decade for those interested in the safety of medicines. Legitimate increasing public interest is providing pressure for even higher standards, and prescribers too are demanding better information which can help them tailor the treatment of individual patients. Meeting these expectations is a major challenge for all concerned. The methods and developments described in this series will take us in the right direction but there remains plenty of scope for innovation if we are to provide patients with the best protection possible.

\section{Reference}

1 Lawson DH. Pharmacovigilance in the 1990s. Br J Clin Pharmacol 1997; 44: 109-110.

(Received 9 December 1997, accepted 6 January 1998) 